\title{
Cyber Harassment and Quality of Life
}

\section{Steinar Thorvaldsen, Anna-Maria Stenseth, Gunstein Egeberg, Geir Olaf Pettersen and John A. Rønning.}

UIT - The Arctic University of Norway

\section{Abstract}

Research on bullying and harassment in Scandinavia has been going on for several decades, and is appearing in new frameworks and forms since the new categories of "cyber harassment" or "cyberbullying" has been introduced. Bullying is a phenomenon of great importance, as it seems to affect persons negatively in their everyday functioning.

We designed a questionnaire on cyber harassment, which was answered by pupils, at five schools in Tromsø $(\mathrm{N}=878)$. This questionnaire included a section of questions concerning traditional forms of harassment and bullying, as well as a set of quality of life (QoL) questions. The main questions asked here are: 1) What is the prevalence in percentages of classical bullying and cyberbullying; 2) Are there gender and/or age differences; 3) What percentage of children bullied classically were also cyber-bullied; 4) In what way was the quality of life affected for those that were classically bullied or cyber-bullied?

Our main finding is that students who report being cyber-harassed or cyber-bullied, report a significantly lower QoL-score than their non-harassed peers, and thus share the same negative characteristics in relation to quality of life as classical harassment and bullying. Cyberbullying is less common than classical bullying, but it now affects some $3.5 \%$ of the pupils, and nearly half of the cyberbullying comes in addition to traditional bullying.

\section{Introduction}

Communications technology clearly has an impact on students and their well-being. Smartphones have become all-in-one devices that combine the functions of a mobile phone with those of a computer, providing online access $24 / 7$. The technology has also provided a new platform for bullying to take place. In this study, we analyse how students in grades 4 to 10 at five schools in the city of Tromsø in Northern Norway $(\mathrm{N}=878)$ replied to a questionnaire 
on harassment, bullying and quality of life. The response rate was $66.5 \%$. The questionnaire comprised three distinct measurement tools; KINDL ${ }^{\mathrm{R}}$ (Jozefiak, Larsson, Wichstrom, Mattejat, \& Ravens-Sieberer, 2008; Ravens-Sieberer \& Bullinger, 2000) which measures children's quality in life (QoL) ; and a traditional and cyberbullying questionnaire. The aim of the study was to investigate two different aspects of peer harassment; classical and cyber, in order to determine whether these different forms of bullying differ between genders, ages or QoL.

We employ the term classical bullying to refer to the "traditional" types of bullying (mobbing in Norwegian) with which we are familiar in schools, and as established by Olweus and subsequently by Roland. This is to differentiate between classical bullying, which takes place in everyday life, and cyberbullying, which occurs online, and/or via e.g. mobile phones. We use different terms to describe specific negative acts: harassment, victimization, teasing, or abuse (Arora, 1994; Kowalski, Limber, \& Agatston, 2012; Mynard \& Joseph, 2000; Rønning, Handegaard, \& Sourander, 2004; Peter K. Smith, Cowie, Olafsson, \& Liefooghe, 2002). We will call this harassment; this term thus refers to specific acts, in accordance with Rønning and Smith.

\section{Background}

\subsection{Traditional harassment and bullying}

In Norway, research has focused on harassment and bullying for about 30-40 years, during which time Olweus and Roland have contributed a great deal to the study of bullying. The research interest in the field of bullying evolved in Scandinavia in the sixties and seventies (Heinemann, 1973; Olweus, 1978). Bullying is commonly regarded a subcategory of aggression. Olweus defined bullying in the following terms:

"A student is being bullied or victimized when he or she is exposed, repeatedly and over time, to negative actions on the part of one or more other student" (Olweus, 1993:9) Olweus (2013) emphasizes three criteria in bullying, namely; intentional negative acts, committed repeatedly and over time, and involving a certain imbalance of power and strength. He also expands the definition and includes specific forms of bullying, such as saying mean and hurtful things, ignoring or excluding, hitting, telling lies and spreading false rumours. 
On the other hand, Monks and Smith (2006) point out that not all researchers agree on this definition of bullying. Some may regard an action that is not intended to do harm as bullying, if the victim regards it as such. Nor does the attempt necessarily have to be repeated if it has caused long-lasting fear of repetition (ibid). Furthermore, the exact wording of the definitions used differs, making comparisons across studies difficult (Vivolo-Kantor, Martell, Holland, \& Westby, 2014).

What most definitions have in common is that bullying is described as a set of negative, unfriendly or aggressive actions. The term aggressive action or aggression implies intent, as a negative behaviour based on a deliberate or unconscious desire to harm the victim (Monks \& Smith, 2006). That said, we need to bear in mind that there are differences in opinion regarding how to operationalize the term bullying. This fact is likely to influence prevalence estimates.

Earlier studies show that roughly five per cent of Norwegian school pupils, perhaps even more, are being harassed at least once a week, and that the number of victims sink according to age (Olweus, 1993; Pellegrini \& Long, 2002; Roland, 2014). Amongst the youngest pupils, the proportion is six to eight per cent, and amongst the oldest it is two to four per cent.

Researchers have attempted to find reasons why some pupils are bullies while others become victims. Olweus suggested that typical victims are more anxious and insecure than students in general. They are also quieter and more sensitive, and are often lonely at school and not aggressive. Frisén (2010) states that in adolescence, peers are important, and if you are unpopular or rejected by friends, this can be the loneliest time of your life. Jansen et al. (2011) found that anxiety, emotional and motor problems, socioeconomic status and family breakup to be important predictors of bully involvement.

In a study of 15 Norwegian primary schools, (Roland, 2014) found that in schools with poor leadership there was more bullying. This was also the case if staff did not cooperate well, especially with regard to educational issues. The same opinion is also to some degree supported by the NIFU report (Lødding \& Vibe, 2010). Various studies indicate that classroom management and structure may have an important impact on bullying (Lødding \& Vibe, 2010; Roland, 2014; Wendelborg, 2014). These studies considered several aspects of classroom and school management, including teachers care for individual students, their ability to teach and 
organize, and to control and intervene. It was also found that generally well-run schools, with a digital learning platform and a good school administration, had lower levels of bullying.

Arora (1994) published a checklist aimed at clarifying the actual extent of bullying experienced by pupils in the course of a week. This approach is an alternative to the global item approach. Arora based her list on three different categories of traditional harassment: physical, verbal and social, and found this checklist to be "an indirect but more precise measurement of bullying", as there are many different types of bullying, and several different definitions of bullying. Many teachers may find the term "bullying" too emotive and suggest that children would not provide reliable responses to such a direct question, and after an intervention a higher number of incidents as "bullying" may be reported, due to the awakening of sensitivity. Arora also stated that her "Life in school" checklist provides direct data of actual bullying incidents as selfreported by students. Thus, data obtained are based as closely as possible on actual occurrences rather than opinion (1999:21). While bullying is an abstract term and maybe difficult to grasp, harassment is more easily understood, as it refers to specific incidents.

\subsection{Cyber harassment and cyberbullying}

Cyber harassment and cyberbullying make up a relatively new field for researchers, obviously, since the devices used in this form of bullying have emerged fairly recently. We therefore need to establish what should be included in the term cyber harassment, as it includes a wide spectrum of behaviours.

There is some inconsistency regarding how to look upon cyberbullying and cyber harassment. Some researchers emphasize typology and view cyberbullying as a new category of bullying, while others emphasize location or environment and make distinctions of where the incident happen (Ybarra, Boyd, Korchmaros, \& Oppenheim, 2012). Tokunaga (2010) lists several rather different definitions used in research and calls for more work to be done on theories and definitions. Olweus (2013) argues that the definition of cyberbullying should derive from the one used in traditional bullying.

Using the same terms as Olweus in his definition of bullying, Peter Smith et al. (Peter K. Smith et al., 2008) defined cyberbullying as; 
An aggressive, intentional act carried out by a group or individual, using electronic forms of contact, repeatedly and over time against a victim who cannot easily defend him or herself.

Menesini et al. (2012), compared the understanding of cyberbullying among adolescents in six European countries. Here they looked at whether the three criteria formed by Olweus for defining classical bullying also could be applied to cyberbullying; intentionality, repetition and imbalance of power.

When studying intentionality, qualitative research has found that young people regard it as cyberbullying when the perpetrator intends to harm another person. Furthermore, they argue that in the virtual context a single aggressive act can lead to an immense number of repetitions of the victimisation, without further direct contributions of the original perpetrator (Ersilia Menesini et al., 2012:455; Slonje \& Smith, 2008).

From this, we may interpret that repetition needs to be further studied, since a single act can be shared and viewed a number of times. Olweus has investigated whether cyberbullying items would relate differently from classical bullying items to a variable with which these items can be expected to correlate (Olweus, 2013: 758). In this study he found that the three key criteria in traditional bullying seem to function in roughly the same way in cyberbullying. He further found that "Students who were exposed to cyber bullying more often tended to have systematically poorer self-esteem" (Olweus, 2013:758). This is in accordance with classical bullying situations. We still know little about long-term impacts of cyberbullying or whether cyberbullying has less impact on the individual than other forms of bullying.

Regarding the criterion of imbalance of power, Menesini et al. (2012) suggested that this criterion may differ in cyberbullying, since victims can use other strategies to "avoid" perpetrators. They also refer to two other criteria that have been suggested as being specific to cyberbullying; namely anonymity and public versus private.

The possibility of anonymity in cyberbullying is unique for this mean of bullying, and it could leave the victim feeling powerless. They further state that, when dealing with public versus private, young people consider it to be more serious if an embarrassing picture is posted publicly, as the audience is larger than if it is sent privately. 
Another study by Menesini et al. (2011:460) singled out different criteria for cyberbullying. The clear first dimension is imbalance of power, and a clear second dimension is intentionality, while at a lower level they identified anonymity. This indicates that students look at two out of three traditional bullying criteria as relevant to cyberbullying, namely intentionality and imbalance of power, but excluded repetition. Imbalance of power may suggest that this is based not only on the social status, popularity or strength of the person who bullies, but on a more interactional description (Menesini et al., 2012). Regarding intentionality, there must be a conscious wish to harm another person in order to consider it as cyberbullying; otherwise, the behaviour is regarded as a joke. Menesini et al. (2012) suggest that anonymity might change its impact on perception in relation to the other criteria and needs to be considered together with other criteria in order to be fully understood.

The public versus private criterion did not show any relevance for the definition of cyberbullying in the study by Menesini et al. They found that students regarded it as cyberbullying whether or not it was sent to a larger audience. Nevertheless, this may be considered a criterion in combination with other criteria (Menesini et al., 2012).

The literature discussed above thus suggests that cyberbullying should be defined by these three criteria: imbalance of power, intentionality and anonymity. Concerning repetition, there appear to be a variety of opinions. Nevertheless, the precise definition ought to be further investigated.

Kowalski et al. provided a brief overview of the different forms of cyberbullying. Flaming "refers to a brief, heated exchange between two or more individuals that occurs via any communication technology... flaming occurs in "public" settings..." (Kowalski et al., 2012:62). In cyberbullying literature, harassment is more one-sided than flaming. Denigration is described as "information about another that is derogatory and untrue" (Kowalski et al., 2012:63), and impersonation is a matter of posing as the victim, the most usual form being to access the victim's social media accounts and harass others, pretending to be the victim. Outing and trickery refer to sharing personal, often embarrassing, information with others, and tricking someone into revealing personal information about themselves and then sharing this with others. Exclusion/ostracism takes place when someone is excluded from for example a Facebook group or is "unfriended" on social network sites. Another form of cyberbullying is to cyberstalk, which refers to using electronic communications to stalk another person through repetitive harassing and threatening communications (Kowalski et al., 2012:67). The authors 
then discuss video recording of assault or 'happy slapping' and hopping, which are ways of utterly humiliating a target by digitally recording assaults on her or him and uploading the recording to the Internet. In happy slapping, one person approaches and slaps someone while another person records the action, while hopping involves direct assaults. Finally, sexting refers to the sending or posting of nude or semi-nude pictures or videos via text messages or other electronic means (Kowalski et al., 2012:68). All the categories above show that cyberbullying can take many forms. Kowalski et al. also describe the most frequently used methods of cyberbullying as; instant messaging, electronic mail, text messaging, bash-boards (online bulletin boards) and social networking sites.

Staksrud (2013), refers to the most common forms of cyberbullying as "someone sent me an insulting/ mean message on the Internet", this is common among all groups of students, but most common among 15 - 16-year-olds. The second most common form Staksrud found was "someone posted an insulting/mean message on the Internet so other could view it, or sent it to another". She has also pointed to seven major differences between cyberbullying and traditional bullying.

1. You can never get away from it

2. Audio-visual material can be used to bully

3. Bullying can be documented

4. The bully can easily hide behind anonymity

5. Cyberbullying leads to new forms of exclusion, in the shape of digital isolation

6. Bullying can become more visible

7. Bullying can become less visible to parents, teachers and other adults.

Smith et al. (2012; 2002) divided cyberbullying into seven sub-categories; Text message bullying, Picture/ Video Clip bullying (via mobile phone cameras), Phone call bullying (via mobile phones), Email bullying, Chat-room bullying, Bullying through instant messaging and Bullying via websites.

In a study involving 3767 students in grades $6-8$, Kowalski and Limber found that although $78 \%$ of the students surveyed had no experience of cyberbullying, while $11 \%$ were victims of cyberbullying, 7\% were both bullies and victims, and 4\% were bullies (Kowalski \& Limber, 2007). No clear influence of either gender or age has been confirmed in cyberbullying, even if there are some reports indicating that girls are more at risk of being targeted (Tokunaga, 2010). 


\subsection{Quality of life}

Quality of life can be understood in many different ways, and there are various definitions of this term. Frisch (2013:202) refers to other and states;

"...the current conceptualizations include the constructs of happiness, well-being, subjective well-being, and life satisfaction, most emphasis is placed on behavioural competencies or "functional ability", which is often unrelated to well-being or happiness."

According to Wallander \& Schmitt (2001:572), quality of life is by its nature a holistic concept, an attempt to describe how well or poorly life works at a particular point in time.

Jozefiak et al. (2008:2-3), defined quality in life (QoL) as "the subjective reported well-being in regard to the child's physical and mental health, self-esteem and perception of own activities (playing/having hobbies), perceived relationship to friends and family as well as to school."

From this one could suggest that QoL could be looked upon as the ways in which a person perceives his or her social, physical and emotional functioning and how she or he manages life. This is a simplified way of attempting to describe a complex term. But like to other abstract terms, such as bullying, quality of life cannot be described in a simple way, or as Jozefiak et al. (2009) state; there is "no gold standard for the definition of QoL".

In a review article, Huebner (2004) addresses the fact that relevant indicators of subjective QoL in the school context have not been agreed upon, although there are findings which indicate that life satisfaction may be relevant to school functioning. This suggests that there is something to gain from studying possible associations between QoL and bullying. The negative effect of bullying on pupils' perception of quality is made evident for the psychosocial QoL, but not for physical (Wilkins-Shurmer et al., 2003). Allison et al. (2009) found impact of bullying in young age on health related quality of life (HRQoL) in adulthood.

Research on the impacts of bullying reveals that victims, among many other effects, suffer a poorer experience of quality of life (Wilkins-Shurmer et al., 2003; Frisén \& Bjarnelind, 2010). Flaspohler et al. (2009) indicate that for children who are bullied but enjoy the social support of their peers, there was a weaker association between bullying and QoL, while those who received support only from teachers did not display this effect. They further found that a 
combination of peer- and teacher support provided the strongest buffer against the negative effect of bullying (ibid).

\section{Materials and Methods}

\subsection{Samples}

The analysis presented in this chapter is a part of the project "Well-being in Tromsø", of UIT the Arctic University of Norway. The data were collected during late autumn 2013 and early spring 2014. Special classes with pupils from other countries than Norway were excluded because these lacked sufficient competence in the Norwegian language. The project "Wellbeing in Troms $\varnothing$ " uses a range of methods to gain information and understanding of students' self-perceived bullying and their self-perceived QoL. Here we seek to obtain a wide spectrum of descriptions of these phenomena, and the possibility of investigating connections from a statistical perspective.

We designed a questionnaire that was completed by pupils at five schools in Tromsø. The questionnaire consist of three measurement instruments; the $\mathrm{KINDL}^{\mathrm{R}}$ quality of life (QoL) questionnaire (Jozefiak et al., 2008; Ravens-Sieberer \& Bullinger, 2000); and a separate section of questions about classical and cyber harassment including the "My Life in School" Checklist (Arora, 1994; E. Menesini et al., 2011; Rønning et al., 2004).

The study was carried out digitally using Questback, which is a commercial tool developed for use in a wide range investigations. Questback has a good reputation for data security. Lower secondary school pupils are under 16 years old, so their parents needed to consent to their participation in the survey. The parents were contacted by the local school, given written and oral information about the project, and asked for their consent.

The students were from a target five-school sample of 1321 students aged 9-16 in 2013-14. The final response rate was $66.5 \%$ of the students in grades 4 to $10(\mathrm{~N}=878)$, and the sample comprised 438 girls and 438 boys, with two cases missing gender identification. The sample consists of $342(31 \%)$ primary level students and $536(69 \%)$ lower secondary level students. 
Written consent is given by parents to all participating pupils. The project is approved by the Regional Ethical Committee for Medical Research, REK-Nord.

\subsection{Measures}

The student questionnaire consists of 24 items for the KINDL questionnaire (Ravens-Sieberer \& Bullinger, 2000), 15 items for traditional harassment (Rønning et al., 2004), eight items for digital harassment, 10 items for bullying (global), six for perception of intervention in bullying incidents, items on gender involvement, and items for background variables.

$\mathrm{KINDL}^{\mathrm{R}}$ measures experienced quality of life (QoL). The questionnaire consists of 24 Likertscale items associated with six dimensions as listed in Tables 6 and 7. The sub-scales of these six dimensions can be combined to produce a total score (TQoL). These dimensions consist of four questions from each of the following categories:

a) experienced physical health (I felt ill, I was in pain, I was tired or worn out, I felt strong and full of energy)

b) emotional well-being (I laughed and had fun, I was bored, I felt alone, I felt scared and unsure of myself)

c) self-esteem (I was proud of myself, I felt on top of the world, I felt pleased with myself, I had lots of good ideas)

d) relationship to family (I got on well with my parents, I felt fine at home, we quarrelled at home, I felt restricted by my parents)

e) relationship to friends (I did things together with my friends, I was a "success" with my friends, I got along well with my friends, I felt different from other people)

f) relationship to school (doing the schoolwork was easy, I found school interesting, I worried about my future, I worried about getting bad marks or grades).

Every question asks about the previous week's experiences, and is scored on a five-point Likertscale (1="never", 2="rarely", 3="sometimes", 4="often" and 5="always"). The 24 items in $\mathrm{Kindl}^{\mathrm{R}}$ use these scales. Mean item scores are calculated for all the subscales. Correlations with comparable QoL scales have shown acceptable validity as well as satisfactory discriminant 
validity (Jozefiak et al., 2009). Ten of the QoL items had reverse-order scaling, meaning that a higher item implies a poorer quality of life.

The classical harassment inventory consists of 15 items from the Arora "Life in School Checklist" (Arora, 1994). The measures use descriptive events, both positively and negatively perceived. Particularly salient questions were selected by Rønning et al. (2004) when the list was being revised, after similarities with other victimization scales were taken into account. In the final version traditional harassment is operationalized by 15 items investigating five verbal, six social and four physical items. The study by Rønning et al. demonstrated acceptable psychometric properties.

The cyber part of the survey is based on a questionnaire developed by Smith et al. (P.K. Smith, Mahdavi, Caravalho, \& Tippett, 2006) and Menesini et al. (E. Menesini et al., 2011). We investigated cyber harassment from two perspectives: cyberbullying in general, which consists of five general variables, and specific forms of cyber harassment, which consists of eight items that present a set of event descriptions. The questions ask how often the respondent has experienced any such events, which include "mean text messages or unpleasant photos/videos on my phone" and "mean calls to my mobile phone". The definition of E-mail insults is "scary or nasty e-mails". The three next items specify "insults online (Facebook, Twitter or web)", "teased or insulted by chat messages, as on Skype or within games" and "insults on blogs". One separate item describe posting picture and video content: "unpleasant photos or videos of me posted on internet (Facebook, YouTube, web and so on)". The last item has a description of social exclusion in cyberspace: "Banned me from a Facebook-group or the like where I wanted to participate".

For the items investigating harassment and bullying frequencies, we also employed a five-point scale. Values are: 1="never", 2= "only once or twice", 3="two or three times a month", 4= "about once per week" and 5="several times a week". The items on classical harassment use these scales, so do the items of cyber harassment. The cut-off point for being harassed/bullied was set to "two or three times a month" or more often. This is a well-known cut-off point in the bullying literature (Arora, 1994; Olweus, 1993; Roland, 2014; Rønning et al., 2004; Peter K. Smith et al., 2002). 


\subsection{Analysis}

For analysis of reliability, we computed Cronbach's alpha for all subscales as a measure of internal consistency. We investigated differences regarding harassment and well-being between groups defined by gender or age by the chi-squared test. Student's t-test was used to determine whether there was a substantial difference between means. Effect sizes were estimated by Cohen's d-value, with Cohen's conventions: 0.2=small effect, $0.5=$ medium, and $0.8=$ large effect (King et al., 2011: 267). All the analyses were performed using SPSS ver. 23 (Windows).

\section{Results}

The fundamental concepts of this paper: bullying, harassments and quality of life are first dealt with in general terms that provide descriptive information, and subsequently in greater depth. The final part of this section deals with the relationship between cyber bullying/harassment and QoL.

\subsection{Reliability}

The reliability Cronbach's alpha measures yielded a value of $\alpha$ ranging from 0.61 to 0.82 for the QoL subscales, and 0.89 for the overall QoL questionnaire.

\subsection{Bullying and Harassment}

\section{Table 1. Self-perceived total bullying and harassment by gender}

The Yes-column shows the incidence of harassment of students who reported being harassed (classical and/or cyber) two or three times a month or more often, and the No-column shows the number of reports of fewer or no occurrences. The p-values are computed by the chi-square test.

\begin{tabular}{|c|c|c|}
\hline & $\begin{array}{l}\text { Bullying } \\
\text { (classical and/or cyber) }\end{array}$ & $\begin{array}{l}\text { Harassment } \\
\text { (classical and/or cyber) }\end{array}$ \\
\hline & No $\quad$ Yes & No $\quad$ Yes \\
\hline Girls & 395 & 316 \\
\hline Boys & 390 & 287 \\
\hline p-value & 0.58 & 0.041 \\
\hline
\end{tabular}

Table 1 shows all reported bullying and harassments (traditional and/or cyber) as split between girls and boys. The table does not support the presumption that girls and boys experience 
harassments equally (p-value 0.041), although the distribution of bullying is more equally distributed among the genders.

Table 2. Self-perceived bullying and harassment by form and gender

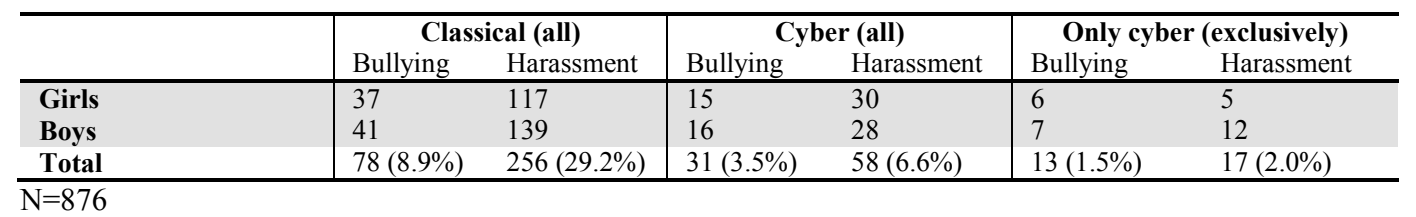

Altogether, 78 students reported to be classically bullied and 13 reported to be bullied only by cyber, hence 91 students (10.4\%) reported either "traditional" or cyberbullying. The overlapping group of both classical and cyber bullied consists of $31-13=18$ students $(2.1 \%)$. The numbers of bullied girls and boys were quite similar, at $37+6=43$ girls and $41+7=48$ boys. More occurrences of harassment are reported than bullying. Both the classical and the exclusive cyber-only domains offered a slight bias towards girls, although the difference was not significant ( $p$-value $>0.05$ by the chi-square test). The difference between genders summed up for the classical and cyber harassment rates are larger, as also shown in Table 2.

The traditionally bullied group comprised 78 students. We also wanted to investigate the extent to which the cyber-bullied group is related to the group of traditional bullies. Within the traditional group, 18 students also reported having been be cyber-bullied, so within the "traditional" group the relative risk of experiencing cyberbullying is $18 / 78=0.23$. The complementary group of students, i.e. those who did not suffer traditional bullying, was at a relative risk of $13 / 800=0.02$ of suffering cyberbullying. The comparable risk factors based on harassments were $41 / 256=0.16$ and $17 / 620=0.03$, respectively.

Table 3. Cyberbullying and cyber harassment by school level

The Yes-column shows the incidence of cyberbullying and cyber harassment of students who reported being bullied/harassed two or three times a month or more often, while the No-column shows the number of reports of fewer or no occurrences.

\begin{tabular}{l|lc|lc}
\hline & \multicolumn{2}{|c|}{ Cyberbullying } & \multicolumn{2}{c}{ Cyber harassment } \\
School & No & Yes & No & Yes \\
\hline Primary (grade 4-7) & 330 & 12 & 330 & 12 \\
\hline Secondary /grade 8-10) & 517 & 19 & 490 & 46 \\
\hline p-value (Chi-square test) & \multicolumn{2}{|c|}{0.98} & \multicolumn{3}{|c}{0.003} \\
\hline $\mathrm{N}=878$
\end{tabular}

Table 3 compares students attending primary and secondary schools. There is a significant difference in the incidence of cyber harassment between primary and secondary schools (pvalue $=0.003$ ). This is natural because of more extensive access to technology for older students, 
and i.e. Facebook requires all users to be over the age of 13. No significant differences between school levels were observed for cyberbullying.

Table 4. Types of cyber harassment

\begin{tabular}{llll}
\hline $\begin{array}{l}\text { Personal } \\
\text { (SMS, mail, } \\
\text { chat, calls) }\end{array}$ & $\begin{array}{l}\text { Public verbal } \\
\text { (blog, social } \\
\text { media) }\end{array}$ & Public visual & $\begin{array}{l}\text { Social } \\
\text { exclusion }\end{array}$ \\
\hline $5.4 \%$ & $2.7 \%$ & $0.9 \%$ & $0.6 \%$ \\
\hline $\mathrm{N}=878$ & & &
\end{tabular}

Table 4 shows the types of cyber harassment to which students reported that they had been exposed. The most common form of cyber harassment is personal messages, and the second most common is public online messages.

\subsection{Quality of life vis-à-vis bullying and harassment}

Table 5. Self-perceived quality of life vs. bullying

The table also shows the total construct TQoL and effect size (Cohen's d)

\begin{tabular}{lllll|llll}
\hline \multicolumn{3}{l}{ Classical } & & & & Cyber & & \\
\hline & $\begin{array}{l}\text { Non-bullied } \\
\text { Mean (SD) }\end{array}$ & $\begin{array}{l}\text { Bullied } \\
\text { Mean (SD) }\end{array}$ & $*$ p-value & $\begin{array}{l}\text { Effect } \\
\text { size }\end{array}$ & $\begin{array}{l}\text { Non-bullied } \\
\text { Mean (SD) }\end{array}$ & $\begin{array}{l}\text { Bullied } \\
\text { Mean (SD) }\end{array}$ & $\begin{array}{l}\text { *p-value } \\
\text { Effect } \\
\text { size }\end{array}$ \\
\hline TQoL & $3.8(.49)$ & $3.3(.55)$ & $<0.001$ & .96 & $3.8(.51)$ & $3.3(.59)$ & $<0.001$ & .91 \\
\hline Physical & $3.8(.63)$ & $3.3(.75)$ & $<0.001$ & .72 & $3.7(.64)$ & $3.4(.86)$ & .036 & .40 \\
Emotional & $4.0(.60)$ & $3.5(.77)$ & $<0.001$ & .72 & $4.0(.62)$ & $3.4(.87)$ & .001 & .79 \\
Self-esteem & $3.4(.82)$ & $3.0(.95)$ & $<0.001$ & .45 & $3.4(.83)$ & $3.0(1.03)$ & .003 & .43 \\
Family & $4.1(.63)$ & $3.7(.81)$ & $<0.001$ & .55 & $4.1(.64)$ & $3.6(.90)$ & .002 & .64 \\
Friends & $4.0(.64)$ & $3.5(.86)$ & $<0.001$ & .66 & $4.0(.66)$ & $3.5(.97)$ & .011 & .60 \\
School & $3.6(.69)$ & $3.2(.65)$ & $<0.001$ & .60 & $3.6(.69)$ & $3.1(.66)$ & $<0.001$ & .74 \\
\hline
\end{tabular}

$\mathrm{N}=878 .{ }^{*}$ Bullied vs. Non-bullied

Table 5 presents the results for the relationship between self-perceived QoL, classical bullying and cyberbullying. Here we observe that the non-bullied score significantly higher in absolutely all categories of QoL. The same tendencies are observed within the cyber domain, although the p-values are somewhat higher, presumably because of a lower sample size.

Students who report not having been bullied reported better overall QoL than those who reported bullying. This is also significant on all constructs in Table 5. The construct with the largest effect size is "TQoL" (0.91-0.96) and "Emotional" (0.72-0.79), while "Self-esteem" has the lowest (0.43-0.45), except for cyberbullying where "Physical" has a slightly lower effect. Most of the effects are between medium (0.5) and large (0.8) (King et al., 2011: 267). 
Table 6. Quality of life for the "pure" cyber-bullied domain versus the non-bullied domain

The total construct TQoL is also shown. In the second half of the table the Non-harassed and solely cyber-harassed groups are also compared. The effect size (Cohen's d) is also shown.

\begin{tabular}{|c|c|c|c|c|c|c|c|c|}
\hline & \multicolumn{4}{|c|}{ Cyberbullying only } & \multicolumn{4}{|c|}{ Cyber harassment only } \\
\hline & $\begin{array}{l}\text { Non-bullied } \\
\text { Mean (SD) }\end{array}$ & $\begin{array}{l}\text { Bullied } \\
\text { Mean (SD) }\end{array}$ & *p-value & $\begin{array}{l}\text { Effect } \\
\text { size }\end{array}$ & $\begin{array}{l}\text { Non-harassed } \\
\text { Mean (SD) }\end{array}$ & $\begin{array}{l}\text { Harassed } \\
\text { Mean (SD) }\end{array}$ & $* *$ p-value & $\begin{array}{l}\text { Effect } \\
\text { size }\end{array}$ \\
\hline TQoL & $3.8(.49)$ & $3.6(.54)$ & .12 & .39 & $3.9(.48)$ & $3.6(.47)$ & .035 & .63 \\
\hline Physical & $3.8(.63)$ & $3.5(.95)$ & .40 & .37 & $3.8(.61)$ & $3.5(.69)$ & .030 & .46 \\
\hline Emotional & $4.0(.60)$ & $3.7(.74)$ & .07 & .45 & $4.1(.59)$ & $3.9(.39)$ & .42 & .40 \\
\hline Self-esteem & $3.4(.82)$ & $3.3(.91)$ & .61 & .12 & $3.5(.82)$ & $3.3(.92)$ & .24 & .23 \\
\hline Family & $4.1(.62)$ & $3.8(.87)$ & .21 & .40 & $4.2(.59)$ & $4.0(.78)$ & .20 & .29 \\
\hline Friends & $4.0(.64)$ & $4.1(.49)$ & .51 & -.18 & $4.1(.62)$ & $3.8(.51)$ & .038 & .53 \\
\hline School & $3.6(.69)$ & $3.2(.78)$ & .029 & .54 & $3.7(.68)$ & $3.4(.72)$ & .14 & .43 \\
\hline
\end{tabular}

We also wished to find out whether the same tendencies were found when analysing QoL in relation to the group who are only exposed to cyberbullying or cyber harassment. We first excluded "traditional" bullying victims from the data, and then compiled the statistics based on the subset of non-cyberbullied vs. cyberbullied groups. We did the same for cyber harassment, as shown in the right hand part of Table 6 . The table reveals the same tendencies for bullying as for harassment, namely that those reporting that they had been be solely cyber victimized, also report poorer QoL. This is significant $(\mathrm{p}<0.05)$ for four out of 14 constructs, and only one of which points in the opposite direction ("Friends"). These results are less certain since the samples are small.

We note that those who report being bullied tended to report lower satisfaction than those who report not being bullied. Tables 5 and 6 both show that students are most content with their family and friends, and somewhat less satisfied with school and their self-esteem.

\section{Discussion}

Arora (1994) viewed bullying as an abstract term, and states that in order to distract attention from the bullying perspective, the questionnaire would benefit from neutral items (some positive or neutral and some more unpleasant). In this study we study both the abstract term 
and the operationalised term (harassment). Both terms tells much the same story when compared.

As mentioned in the theoretical framework, many studies have attempted to find out which gender is more likely to bully and be bullied. There seem to be general agreement among researchers that boys engage in bullying more than girls (Kowalski et al., 2012; Olweus, 1993; Pellegrini \& Long, 2002; Roland, 2014), but that there may be an shift today in Norway (Wendelborg, 2014). This is consistent with the results of this study, as we find that girls are bullied nearly as much as boys, both by traditional and cyber methods.

The main aim of this study was to determine whether students who report being and/or harassed also report poorer quality of life. Since research has focussed less on bullying and quality of life, this is a relatively new field for research that also takes up the QoL of adolescents. For this reason, there are few studies with which to compare it in detail. Our main finding is that students who are bullied and/or harassed reported themselves to be significantly less content. Cyberharassed students also report a lower QoL (Table 5 and 6). However, students overall reported themselves as being fairly content with life.

Compared to traditional bullying, cyberbullying is less widespread, i.e. $3.5 \%$ versus $8.9 \%$ (Table 1). However, both forms of bullying and harassment resulted in significantly lower ( $p$ $<0.05$ ) scores on the quality of life scales (Table 6).

\subsection{Quality of life aspects}

Tables 5 and 6 showed that students generally reported good "total quality of life" (score between 3 and 4). They claimed to be most satisfied with their family, followed by friends and emotional well-being, while they reported less satisfaction with school and self-esteem. The standard deviations indicate that there is greater dispersion for some of the constructs, particularly self-esteem, which also yields the lowest mean score. The lowest dispersion was found in the total construct "TQoL".

\subsection{Aspects of bullying and harassment}


Some $10.4 \%$ of the participants reported being classically and/or cyberbullied (Table 2). This is a high percentage compared to other studies; even $8.9 \%$ (those who reported having been "traditionally" bullied) is a relatively high rate for Norway. Olweus and Roland estimate that 5\% of children in Norway are bullied (Olweus, 2013; Roland, 2014). In The Student Survey of 2013 found that $4.2 \%$ reported being bullied at school; this is substantially lower than in previous years (6.8\% in 2012) (Wendelborg, 2014). The Student Survey was mainly performed in autumn 2013, while earlier studies took place in spring. This could be one of several possible reasons why they found a drop in bullying incidents, because many students are new to each other when the schoolyear starts in autumn.

Our study was mainly conducted in the autumn, so this is similar to the 2013 student survey. Wendelborg (2014) states that approximately 400000 students took part in that study, while our data are based on the answers given by nearly 900 students. The fact that our study is solely an urban study cannot account for the relatively high percentage of bullying reported. As mentioned in the theory section above, Olweus showed that there is no reason to believe that bullying rates differ between urban and rural districts (Olweus, 1993). While we found that $10.4 \%$ of our students reported having been bullied, we also need to emphasize that this includes both traditional and cyberbullying, both at and outside of school.

Another reason for our high percentage could be that there has been a focus on bullying at school, at home or in the media, leading to a relatively high number of reports of being bullied. Nevertheless, there can be other reasons, such as something happening at school, such as a fight between pupils, a quarrel or something similar which resulted in these responses. In order to find if these figures are stable over time we will need to perform a longitudinal study.

Table 1 shows that more students report having been harassed than bullied. This may be because it is easier to report being for instance hit or kicked than bullied; being bullied one might be regarded a victim, whereas occasional kicking might be treated as isolated incidents.

There has been a debate amongst researchers regarding how to classify cyberbullying. As mentioned above, some consider cyberbullying to be a type of bullying, equivalent to social bullying (Ybarra et al., 2012). In our study we treat it as a new type of bullying. Since this is a relatively fresh field, the debate is understandable and necessary. It is not within the scope of this study to debate this, as we think it calls for further investigation. 
Our figures for cyberbullying show that 3.5\% of all pupils reported that they had been cyberbullied, $1.3 \%$ reported such bullying took place at school, and 3.4\% outside of school. This shows that students report having been cyber-bullied more in their spare-time than at school, and this is similar to reports by other studies (Kowalski et al., 2012; Olweus, 2013). This might be because students know they are not allowed to have mobile phones in the classroom, and therefore do not report such events, or that they actually are more cyber-bullied outside of school hours.

In several studies the figures differ, as some studies report being cyber-bullied when it takes place happened at least once in the previous month, while others use the definition offered by Olweus. The figures of being a target of cyberbullying range from $4 \%$ to - $40 \%$ (Agatston, Kowalski, \& Limber, 2007; Hinduja \& Patchin, 2012; Kowalski et al., 2012; Olweus, 2013). Olweus found that $4.5 \%$ of students, in a study conducted in a large US sample, reported having been cyberbullied, and the numbers were even lower in Norway (Olweus, 2013).

When we ask students how often they are cyberbullied, most of them answer that they have never/only once or twice been bullied, and the definition of bullying does not regard this rate as being bullied. The most frequent answers, from those who report being cyber-bullied in one way or another are "teased or insulted me via chat messages, etc." followed by "teased or insulted me online" and "mean calls to me on my mobile phone", this is similar to what Kowalski et al. found (2012). As mentioned above, the actual numbers of those who report having been cyberbullied are for the time being low, but students in the classical bullying group are at a higher risk of entering the domain of cyberbullying.

\subsection{Aspects of quality of life, bullying and harassment}

Table 5 shows that that both classical and cyber victims report a poorer overall QoL than nonvictims, and there are significant differences in all measures of QoL. We find that victims of bullying are more likely to report lower scores than the group that is not bullied. The study by Frisén \& Bjarnelind (2010) reported similar findings regarding QoL, although the authors used different measures. In a study from USA, Patchin \& Hinduja (2010) found that students who experienced cyberbullying, both as a victim and an offender, had significantly lower self-esteem than those who had little or no experience with cyberbullying. The standard deviations show 
that there is wider variance within the group being bullied than those not bullied, except for the construct "School".

In Table 6 we examine the "pure" cyber domain. The effect sizes here are small to medium on all constructs, except for "Friends", which is opposite. Due to the effect sizes there are reasons to assume that cyberbullying in itself does to some extent affect QoL, while it might not affect friendships to the same extent. This could be because whether or not one is being cyberbullied, one probably still have friends who offer support.

\subsection{Limitations}

A number of choices have to be made in study design, and these choices are essential to the quality of every study. In this study quantitative method is used to address the main topic.

The questionnaire consisted of mutually exclusive questions with a given range of responses, although it included a section in which the respondent could write his/her thoughts and feelings concerning the questions asked. As the informants had a limited range of answers at their disposal, processing these was not too complicated, and we also made sure that the questions were answered at the same level of precision, as advised by Kleven (2011). Students have to answer each question before they are allowed to move on, which reduces the problem of missing responses. On the other hand, this can increase the problem of validity due to the fact that respondents do not necessarily answer truthfully and in line with the assumptions of the design of the study. However, in discussions and interviews with teachers and respondents, done in other parts in this project, there appear to have been few problems associated with not providing correct information.

When we look at the questions that asked about cyber harassment in our questionnaire, one can discuss whether or not they are up to date. The rapid changes in digital devices present a challenge to keeping questions up to date. Many students and teachers say that students do not use e-mails and SMS as much as they used to, so these questions may need to be revised. When we ask students, they say that they hardly use their mobile phones to make calls and send SMS, but use chat on Facebook (Messenger), Instagram and Snap-chat to keep in touch, while new apps keep popping up. The questions used in this study to measure cyber harassment are still at an early stage of development, and will need further validation to become a more consent and acceptable instrument. 


\subsection{Conclusions}

We found that, compared to classical bullying, cyberbullying is less common, but it now affects some $3.5 \%$ of pupils, i.e. more than one third of the level of classical bullying, and most of it takes place outside of school. Nearly half of the cyberbullying (1.5\%) comes in addition to traditional bullying. There are only small gender- and age-related differences in incidence at both primary school (ages 10-13) and secondary school (ages 14-16).

Both "traditional" and cyber forms of bullying and harassment show significantly $(\mathrm{p}<0.05)$ lower scores on their self-perceived quality of life factors, as shown in Table 5. Non-victims reported a mean between $4.1-3.4$ on a scale from 1 to 5 , while those who reported having been bullied reported a mean between 3.7 - 3.0. Cyber harassment and cyberbullying share the same negative characteristics in relation to quality of life as classical harassment and bullying.

This study was carried out in a city in northern Norway. Even though Norwegian society and the educational system are both rather homogeneous in terms of socio-economic status, a broader sampling strategy would have improved generalization. In order to determine whether our results are stable over time, and to produce a more detailed study of causalities between the variables, a longitudinal study will be necessary. The publication of studies in the cyber domain may lead to the development of much-needed theory, policy, education and methods of preventing and intervening in cases of cyberbullying and cyber harassment.

\section{Note}

This paper is partly based on the master's thesis of Anna-Maria Stenseth: "Being bullied, quality of life and gender”. University of Tromsø, Department of Education, 2015.

\section{References}

Agatston, P. W., Kowalski, R., \& Limber, S. (2007). Students' Perspectives on Cyber Bullying. Journal of Adolescent Health, 41(6), S59-S60. doi:10.1016/j.jadohealth.2007.09.003 
Allison, S., Roeger, L., \& Reinfeld-Kirkman, N. (2009). Does school bullying affect adult health? Population survey of health-related quality of life and past victimization. Australian and New Zealand journal of psychiatry, 43(12), 1163-1170.

Arora, T. (1994). Measuring Bullying with the 'Life in School' Checklist. Pastoral Care in Education, 12(3), 11-15. doi:10.1080/02643949409470880

Arora, T. (1999). Levels of Bullying Measured by British Schools Using the "Life in School" Checklist: A Case for Benchmarking? Pastoral Care in Education, 17-22.

Fangen, K. (2004). Deltagende observasjon. Oslo: Fagbokforlaget.

Flaspohler, P. D., Elfstrom, J. L., Vanderzee, K. L., Sink, H. E., \& Birchmeier, Z. (2009). Stand by me: The effects of peer and teacher support in mitigating the impact of bullying on quality of life. Psychology in the Schools, 46(7), 636-649. doi:10.1002/pits.20404

Frisén, A., \& Bjarnelind, S. (2010). Health - related quality of life and bullying in adolescence. Acta Pædiatrica, 99(4), 597-603. doi:10.1111/j.16512227.2009.01664.x

Heinemann, P.-P. (1973). Mobbing : gruppevold blant barn og voksne. Oslo: Gyldendal. Hinduja, S., \& Patchin, J. W. (2012). Cyberbullying prevention and response: expert perspectives. New York: Routledge.

Jansen, D. E., Veenstra, R., Ormel, J., Verhulst, F. C., \& Reijneveld, S. A. (2011). Early risk factors for being a bully, victim, or bully/victim in late elementary and early secondary education. The longitudinal TRAILS study. BMC Public Health, 11(1), 440.

Jozefiak, T., Larsson, B., Wichstrom, L., Mattejat, F., \& Ravens-Sieberer, U. (2008). Quality of Life as reported by school children and their parents: a cross-sectional survey. Health Qual. Life Outcomes, 6. doi:10.1186/1477-7525-6-34

Jozefiak, T., Larsson, B., \& Wichstrøm, L. (2009). Changes in quality of life among Norwegian school children: A six-month follow-up study. Health and Quality of Life Outcomes, 7. doi:10.1186/1477-7525-7-7

Kleven, T. A., Tveit, K., \& Hjardemaal, F. (2011). Innføring i pedagogisk forskningsmetode: en hjelp til kritisk tolking og vurdering. Oslo Unipub.

Kowalski, R. M., Limber, S., \& Agatston, P. W. (2012). Cyberbullying: bullying in the digital age. Malden, MA: Wiley-Blackwell.

Kowalski, R. M., \& Limber, S. P. (2007). Electronic Bullying Among Middle School Students. Journal of Adolescent Health, 41(6), S22-S30. doi:10.1016/j.jadohealth.2007.08.017

Lødding, B., \& Vibe, N. (2010). "Hvis noen forteller om mobbing...": utdypende undersøkelse av funn i Elevundersøkelsen om mobbing, urettferdig behandling og diskriminering Rapport (NIFU : online), Vol. 48/2010.

Menesini, E., Nocentini, A., \& Calussi, P. (2011). The measurement of cyberbullying: dimensional structure and relative item severity and discrimination. Cyberpsychol Behav Soc Netw., 14(5), 267-274. doi:10.1089/cyber.2010.0002

Menesini, E., Nocentini, A., Palladino, B. E., Frisén, A., Berne, S., Ortega-ruiz, R., . . Smith, P. K. (2012). Cyberbullying Definition Among Adolescents: A Comparison Across Six European Countries. Cyberpsychology, Behavior, and Social Networking, 120720083250004. doi:10.1089/cyber.2012.0040

Monks, C. P., \& Smith, P. K. (2006). Definitions of bullying: Age differences in understanding of the term, and the role of experience. British Journal of Developmental Psychology, 24(4), 801-821. 
Mynard, H., \& Joseph, S. (2000). Development of the Multidimensional PeerVictimization Scale. Aggressive Begaviour, 26, 169-178.

Olweus, D. (1978). Aggression in the schools: Bullies and whipping boys: Hemisphere.

Olweus, D. (1993). Bullying at school: what we know and what we can do. Oxford: Blackwell Publ.

Olweus, D. (2013). School bullying: development and some important challenges. Annu Rev Clin Psychol, 9, 751-780. doi:10.1146/annurev-clinpsy-050212-185516

Patchin, J. W.; Hinduja, S. (2010) Cyberbullying an Self-Esteem. Journal of School Health. 80 (12), 614-621.

Pellegrini, A. D., \& Long, J. D. (2002). A longitudinal study of bullying, dominance, and victimization during the transition from primary school through secondary school. Br. J. Dev. Psychol., 20, 259-280.

Ravens-Sieberer, U., \& Bullinger, M. (2000). KINDLr Questionnaire for Measuring HealthRelated Quality of Life in Children and Adolescents.

Roland, E. (2014). Mobbingens psykologi: hva kan skolen gjøre? Oslo: Universitetsforl.

Rønning, J. A., Handegaard, B. H., \& Sourander, A. (2004). Self-perceived peer harassment in a community sample of Norwegian school children. Child Abuse and Neglect, 28(10), 1067-1079. doi:10.1016/j.chiabu.2004.04.006

Slonje, R., \& Smith, P. K. (2008). Cyberbullying: Another main type of bullying? Scandinavian Journal of Psychology, 49(2), 147-154.

Smith, P. K., Cowie, H., Olafsson, R. F., \& Liefooghe, A. P. D. (2002). Definitions of Bullying: A Comparison of Terms Used, and Age and Gender Differences, in a FourteenCountry International Comparison. Child Development, 73(4), 1119-1133.

Smith, P. K., Mahdavi, J., Caravalho, M., \& Tippett, N. (2006). An investigation into cyberbullying, its forms, awareness and impact, and the relationship between age and gender in cyberbullying.

Smith, P. K., Mahdavi, J., Carvalho, M., Fisher, S., Russell, S., \& Tippett, N. (2008). Cyberbullying: Its Nature and Impact in Secondary School Pupils. Journal of Child Psychology and Psychiatry, 49(4), 376-385. doi:10.1111/j.14697610.2007.01846.x

Staksrud, E. (2013). Digital mobbing: hvem, hvor, hvordan, hvorfor - og hva kan voksne gjøre? Oslo: Kommuneforl.

Tokunaga, R. S. (2010). Following you home from school: A critical review and synthesis of research on cyberbullying victimization. Computers in Human Behavior, 26(3), 277-287. doi:http://dx.doi.org/10.1016/i.chb.2009.11.014

Vivolo-Kantor, A. M., Martell, B. N., Holland, K. M., \& Westby, R. (2014). A systematic review and content analysis of bullying and cyberbullying measurement strategies. Aggression and Violent Behavior, 19(4), 423-434. doi:http://dx.doi.org/10.1016/j.avb.2014.06.008

Wallander, J., Schmitt, M., \& Koot, H. (2001). Quality of life measurement in children and adolescents: Issues, instruments, and applications. Journal of Clinical Psychology, 57(4), 571-585.

Wendelborg, C. (2014). Mobbing, krenkelser og arbeidsro i skolen. Rapport NTNU.

Wilkins-Shurmer, A., O'Callaghan, M., Najman, J., Bor, W., Williams, G., \& Anderson, M. (2003). Association of bullying with adolescent health-related quality of life. $J$ Paediatr Child Health, 39(6), 436-441. doi:10.1046/j.1440-1754.2003.00184.x

Ybarra, M. L., Boyd, D., Korchmaros, J. D., \& Oppenheim, J. (2012). Defining and Measuring Cyberbullying Within the Larger Context of Bullying Victimization.(Report). Journal of Adolescent Health, 51(1), 53. 
